\title{
Estudo Preliminar para a Construção da Escala de Autoconceito Infanto-Juvenil (EAC-IJ)
}

\author{
Fermino Fernandes Sisto \\ Universidade de São Francisco \\ Selma de Cássia Martinelli \\ Universidade Estadual de Campinas
}

\begin{abstract}
RESUMO
Esta pesquisa trata da construção e estudo fatorial de um instrumento para avaliar o autoconceito para crianças e jovens nos contextos social, escolar, familiar e pessoal. Foram analisadas as respostas de 555 estudantes, com idades entre 8-16 anos. Deles, 281 (50,6\%) eram do gênero masculino e 274 $(49,4 \%)$ do gênero feminino, freqüentando de segunda a oitava séries do ensino fundamental. Os itens foram eliminados com base na saturação fatorial e na consistência interna e selecionados 20 itens, distribuídos nos quatro fatores pretendidos, explicando $41,09 \%$ da variância. Os coeficientes de consistência interna de Cronbach variaram de 0,59 a 0,62 para os fatores e para a pontuação total foi de 0,78. Assim, foram identificados itens que caracterizam os quatro contextos. Esses dados corroboram a perspectiva da multidimensionalidade do self defendida primeiramente por Mead e James.
\end{abstract}

Palavras-chave: análise fatorial; crianças; jovens.

\begin{abstract}
Preliminary Study for the Construction of the Escala de Autoconceito Infanto-Juvenil (EAC-IJ)

This research deals with the construction and factorial study of an instrument to be used for the assessment of self-concept for children and juveniles in social, scholastic, family and personal contexts. The answers of 555 students, aged between 8-16 years old, were analyzed. This population consisted of $281(50.6 \%)$ males and $274(49.4 \%)$ females, attending second to eighth grades of elementary school. Items were eliminated on the basis of the factorial saturation and the internal consistency, and 20 items were chosen, distributed in the four proposed factors explaining $41.09 \%$ of the variance. The Cronbach's coefficients of internal consistency varied from 0.59 to 0.62 for the factors and for the total score was 0.78. Thus, items characterizing the four contexts were identified. This data corroborates the multidimensional perspective of the self first defended by Mead and James.
\end{abstract}

Keywords: factor analysis; children; adolescent.

Vem de há muito tempo o reconhecimento por parte de psicólogos e pedagogos da necessidade de instrumentos mais adequados e convenientes para avaliar os aspectos afetivos da personalidade de crianças e adolescentes. Tanto em situação clínica como escolar, esse tipo de informação tem-se constituído em um instrumento importante para a tomada de decisões quanto ao encaminhamento de pessoas que estejam apresentando algum problema de adaptação.

A escola tem atualmente ocupado um papel de importância na vida afetiva da criança e do adolescente, ao mesmo tempo em que fornece elementos para eles se autoconhecerem. Na medida em que os educadores se preocupam cada vez mais com o papel construtivo da escola, cresce a necessidade de instrumentos que, aplicados coletivamente, possam ser úteis. Dentre as variáveis afetivas o autoconceito vem ganhando destaque desde que os estudos de James (1890) abriram a possibilidade desse constructo ser mais bem compreendido. Sua mais importante contribuição foi ter pela primeira vez distinguido entre dois aspectos fundamentais do self ou "eu". Por um lado o "eu" como sujeito que, conforme explica Damon (1983), teria a função de organizar e interpretar, de forma subjetiva, as experiências do indivíduo. Por outro lado, o "eu" como objeto, que seria constituído pelas características materiais (corpo, família, bens), pelas características espirituais (estados de consciência, faculdades psíquicas) e pelas características sociais (relações, papéis, personalidade), características essas que conferem ao sujeito a sua individualidade.

Para James o "eu-sujeito" era o conhecedor em contraste com o "eu-objeto" o qual pode ser representado como um agregado de coisas objetivamente conhecidas a respeito do "eu". É o "eu-objeto", que tem sido denominado de autoconceito e que tem rece- 
bido maior atenção por parte dos especialistas preocupados com o estudo psicológico do "eu". No entanto, os modelos teóricos, as limitações e qualidade dos instrumentos e as carências metodológicas na obtenção de dados empíricos, foram o grande entrave no estudo desse constructo (Wylie, 1979; Burns, 1979).

Ainda que pesem tais dificuldades, na literatura pode-se observar uma grande quantidade de pesquisa e problemas levantados em relação ao autoconceito dos estudantes do ensino fundamental, médio ou universitário, demonstração do interesse existente para avaliar essa variável, considerada fonte de informação relevante para explicar a gênese ou o desenvolvimento dos problemas de desenvolvimento, educacionais, adaptativos, entre outros, de crianças e adolescentes. O psicólogo clínico e escolar, os educadores, pesquisadores e psiquiatras infanto-juvenis quando se vêem frente à necessidade de acompanhar o desenvolvimento de uma pessoa de 8 a 16 anos precisam dispor de dados referentes à qualidade das relações que a pessoa estabelece consigo mesma, ao avaliar-se frente a si mesma e a ambientes específicos de seu entorno.

No Brasil, uma boa parte dos instrumentos para avaliar o autoconceito está publicada em dissertações de mestrado, teses de doutorado e artigos, nem sempre de fácil acesso ao grupo de profissionais que necessitam lançar mão desse tipo de avaliação. Há que lembrar também que a maior parte dos instrumentos usados no Brasil são traduções ou adaptações de instrumentos construídos para outras realidades sociais, as diferenças conceituais e estruturais entre eles tornam difícil estabelecer comparações entre os resultados obtidos, na maioria das vezes não se explicita a fundamentação teórica que lhes serviu de base, bem como há que se considerar que os estudos sobre evidências de validade e os dados de precisão nem sempre são conhecidos, e muitos não possuem informações sobre as normas para se comparar e avaliar as pessoas.

Para preencher essa lacuna foi construída a Escala de Autoconceito Infanto-Juvenil (EAC-IJ) com a finalidade de superar algumas deficiências da literatura e poder avaliar com maior precisão os diferentes níveis de autoconceito da criança e do jovem, em distintos contextos sociais, com os quais interage freqüentemente. Assim, nosso ponto de partida foi definir o autoconceito como um produto da interação entre a pessoa e seu meio ambiente, durante seu processo de construção social e ciclo de vida, acompanhada de uma avaliação de suas capacidades, realizações, experiências e representações.

O que esta Escala de Autoconceito Infanto-Juvenil (EAC-IJ) apresenta de diferente das outras escalas não são seus fundamentos teóricos. De maneira geral, o autoconceito tem sido definido por diversos autores como o conhecimento que o indivíduo tem de si, o que inclui aspectos cognitivos, afetivos e comportamentais.

De fato, para sua construção partiu-se do pressuposto de que o autoconceito é multidimensional, no sentido de possuir vários componentes importantes participando de sua constituição. Conforme Burns (1979) e Machargo (1991) essas percepções construídas e as atitudes a elas correspondentes (autoconceito) possuem três componentes básicos. Um componente cognitivo que diz respeito ao conjunto de características com o que a pessoa se descreve e que não é necessariamente verdadeiro ou objetivo, mas que orienta seu modo habitual de ser e se comportar. Um aspecto afetivo que diz respeito aos afetos e emoções que acompanham a descrição de si mesmo e que foi definida por Coopersmith (1967) de auto-estima. E o aspecto comportamental que passa a ser influenciado diretamente pelo conceito que a pessoa tem de si mesma. Acredita-se também no caráter desenvolvimental do autoconceito, assumindo-se assim que o autoconceito começa a ser construído na infância e que sofre o impacto das opiniões dos outros.

Assim, não se teve como base a existência de uma hierarquia entre seus componentes, como proposto por Shavelson, Hubner e Stanton (1976), mas optou-se pela postura teórica defendida por Mead (1934) e James (1890) de que a pessoa pode ter vários "eus" ou vários autoconceitos. Para Mead, os vários "eus" podem se desenvolver em função das diferentes experiências sociais dos indivíduos. Autores clássicos no estudo do autoconceito como Coopersmith (1967), Maccoby (1980) ou Swayze (1980) afirmam que as crianças recebem informações sobre si mesmas dos adultos significativos em sua vida e que dessas impressões recebidas desenvolvem uma imagem positiva ou negativa sobre si mesmos.

Ao lado disso, defendeu-se que os vários autoconceitos seriam construídos com informações e indicadores sociais diferentes. Nessa linha de raciocínio, quando eu estou avaliando como eu me vejo em relação à escola, meus indicadores, assim como as informações que me deram retorno positivo ou negativo, serão diferentes de quando estou me avaliando em relação ao contexto familiar. Na escola e na família os critérios de sucesso ou fracasso, de aceitação ou rejeição, de bonito ou feio também se diferenciam nitidamente. Assim é possível se falar de um "eu" familiar e que corresponde às atitudes frente à família, o "eu" escolar, formado a partir as relações com os professores e colegas entre outros. 
Passou-se a aceitar que o autoconceito dos indivíduos pode apresentar diferenças de acordo com o contexto social em que este é analisado, assim como cada um desses contextos acaba por influenciar de uma determinada maneira o autoconceito dos indivíduos. Essa posição, contrariamente ao modelo apresentado por Shavelson, Hubner e Stanton (1976), não trata o autoconceito de forma hierárquica, mas introduz a idéia da multidimensionalidade desse constructo, posição também assumida por nós neste estudo.

Seguindo a linha de raciocínio de que o autoconceito é multidimensional, a literatura tem apontado para a importância das experiências vivenciadas em diferentes contextos da vida social dos indivíduos como fundamentais na construção do autoconceito. Assim, pode-se dizer que o meio social nos fornece elementos importantes para analisar o autoconceito. Para James (1890) o autoconceito social se refere à percepção das pessoas de o quanto as outras gostamna e admiram-na. Em outras palavras, para esses autores o autoconceito social é definido pela sua percepção de aceitação social. Para outros teóricos, o autoconceito social tem sido definido como a percepção das pessoas sobre sua competência ou habilidades sociais (Blascovich \& Tomaka, 1991; por exemplo). Assim as escalas destinadas à medição do autoconceito social tem variado de acordo com a interpretação dada a esse constructo.

No entanto, apesar das diferentes interpretações, pode-se encontrar entre os teóricos uma concordância quanto ao fato de ser o autoconceito fortemente influenciado pelas relações sociais que se estabelecem entre $o$ indivíduo e o meio, no decorrer de sua existência. Concomitantemente passam tanto pelas percepções dos outros quanto pelas avaliações feitas a nosso respeito (Mead, 1934; Harter, 1985; Tamayo, 1985; entre outros).

Assim como o meio social mais amplo, as relações familiares têm despertado forte e incessante interesse de estudiosos do comportamento humano. O que tem se considerado de família é, segundo Bruschini e Ridenti (1994, p. 31) "unidades dinâmicas de relações sociais, no interior das quais ocorre a reprodução biológica, a socialização e a transmissão de valores", o que pressupõe um modelo constituído por um casal e filhos. No entanto, na prática, sabe-se que esse modelo já não corresponde à realidade dos fatos e já se tem apontado para modificações (Goldani, 1994).

Ainda que pesem essas modificações não se pode negar, como afirma Fini (2000), que é entre os membros de uma família que ocorre o estabelecimento de vínculos, que podem ser harmoniosos, afetivos e solidários ou carregados de raiva e ressentimentos. Se- gundo Allport (1966), é na interação com os pais que a criança percebe o que se espera dela. Coopersmith (1967) e Baumrind (1972) também salientam a importância da família no desenvolvimento de um autoconceito positivo e saudável e a existência de padrões que combinam limites claros e estritos com disciplina firme mas sem negligenciar o calor e afeto, são os mais favoráveis para o desenvolvimento positivo do autoconceito.

Inúmeras são as pesquisas que procuram avaliar o impacto dessas relações ocorridas no interior da família, sobre o comportamento e as atitudes de crianças e jovens e têm sido unânimes em destacar de que maneira a família tem contribuído para a formação de um autoconceito mais positivo e sentimentos de confiança, o que possibilita que as relações com as pessoas em geral seja mais efetiva (Ribeiro, 1987; Lindner, 1992; Zimiles \& Valerie, 1991; entre outras).

As relações presentes no ambiente escolar também têm sido objeto de estudo de diversos pesquisadores. Seu papel excede em muito o que lhe foi primariamente outorgado - a transmissão dos conhecimentos acumulados - pois se trata de um espaço rico de interações e se constitui como um dos maiores agentes de socialização dos indivíduos. Com a entrada para a escola a criança não somente terá que aprender a lidar com as demandas cognitivas que lhe são cobradas, mas também precisará integrar-se a esse novo mundo social. A integração entre os fatores cognitivos e sociais será determinante para o sucesso da criança nesse novo contexto.

O fracasso permanente e perpetuado foi estudado por Adler (1927) quando afirmou que o fracasso pode gerar um sentimento de insegurança e falta de confiança. Se a criança que entra na escola já leva consigo experiências anteriores de fracasso, baseada em suas relações familiares, esse sentimento básico de insegurança poderá se manter, uma vez que toda criança chega na escola com experiências anteriores que já lhe deram uma visão de si mesma. Assim, a escola poderá tanto reforçar essa imagem como propiciar experiências que as modifiquem, uma vez que juntamente com a figura dos pais, os professores agora passam a ser também um referencial para a criança. As outras crianças, por sua vez, passam a ser o referencial de análise em tudo o que se é capaz de realizar nesse momento.

Dessa forma o estudo do autoconceito escolar tem sido destacado tendo em vista a importância dada a esse constructo na dinâmica das relações que ocorrem no ambiente escolar. Desde o final da década de 70 se aceita que um dos fatores principais do rendimento acadêmico é o autoconceito, determinado no contexto 
educativo pela qualidade das relações estabelecidas entre o professor e o aluno (Burns, 1979; Purkey, 1970). As pesquisas desenvolvidas buscando relações entre autoconceito e o desempenho acadêmico tem se avolumado no decorrer dos anos e os resultados dessas investigações apontam para uma persistente e significativa relação entre as duas variáveis (Knowles, 1983; Buchanan \& Wolf, 1986; Jesus \& Gama, 1991; Serrano, 1991; Martins, 1997; Silva, 1999; por exemplo), embora as relações entre o autoconceito geral e o rendimento acadêmico sejam relativamente baixas (Wylie, 1979; Hansford \& Hattie, 1982; Byrne, 1986).

Também se verifica a tentativa de encontrar relações entre esse constructo e as dificuldades de aprendizagem, evidenciando-se que os sujeitos que apresentam maiores dificuldades têm apresentado um autoconceito mais rebaixado que seus pares sem dificuldades (Marsh, Smith \& Barnes, 1985; Cooley \& Ayres, 1988; Durrant, Cunninghan \& Volker, 1990; Jesus \& Gama, 1991; Seco, 1993; Estevão \& Almeida, 1999; Carneiro, Martinelli \& Sisto, 2003).

Dentre os fatores analisados, e que podem influenciar o autoconceito, os aspectos físicos também merecem ser destacados. A aparência física tem freqüentemente sido destacada como elemento indiscutível para a maior aceitação dos indivíduos pelo meio social, contribuindo para que sejam mais populares, tenham um tratamento preferencial, sejam mais aceitos pelo grupo, entre outras vantagens percebidas. Os estudos na sua grande maioria realizados nas décadas de 60 e 70, encontraram correlações positivas entre as pessoas fisicamente atrativas e o autoconceito (Adams, 1977; Lerner, Orlos \& Knapp, 1976; por exemplo).

À medida que avançam os estudos sobre o autoconceito, e que se reforçam suas bases e seu caráter multidimensional, também se afunilam cada vez mais o estudo de variáveis que possam estar relacionadas a esse constructo. Tradicionalmente têm sido apontadas razões para se sugerir que o autoconceito também pode variar com a idade e o gênero.

Os estudos sobre as diferenças de idade e autoconceito não têm sido consensuais a respeito de sua influência no autoconceito multidimensional de crianças e adolescentes, não sendo vista por muitos autores como tendo relação com o autoconceito de crianças e adolescentes, mas no tipo de relação que estabelecem com seus pais (Bracken \& Crain, 1994; Furman \& Buhrmester, 1992). Assim, a qualidade da relação entre a criança e seus pais piora com o advento da adolescência (Bracken \& Crain, 1994; Furman \& Buhrmester, 1992), voltando-se o adolescente mais para seus pares. No entanto, também tem sido desta- cado que esses conflitos não chegam a modificar substancialmente a percepção positiva do "eu".

Também tem se verificado que em outros domínios do autoconceito a idade pode ter um papel menor. A idade parece influir na percepção da criança sobre suas habilidades através de seu progresso nos níveis de ensino. Entretanto, autores como Stipek (1981) atribuem o produto de seu autoconceito não a uma idade particular mas ao feedback de uma avaliação externa de seu desempenho.

Os estudos sobre o gênero têm argumentado que existem diferenças cruciais entre os dois grupos e que estas contribuiriam para as diferenças no autoconceito. No entanto, como visto em relação à idade, as diferenças apontadas no autoconceito de meninos e meninas são ambíguas, inconsistentes e os estudos apresentam-se metodologicamente inadequados, uma vez que apontam simplesmente para o autoconceito global mais elevado de meninos em relação ao das meninas (Harter, 1990; Ribas, 1994).

Desde que Shavelson e colaboradores propuseram um modelo de estudo do autoconceito, essa área avançou consideravelmente e se fortalece a cada dia. A aceitação da noção multidimensional do autoconceito tem ganhado adeptos a cada dia que passa e seu debate estende-se cada vez mais para os domínios da educação, psicoterapia entre outros.

Entretanto, permanecem ainda alguns pontos que precisam ser esclarecidos e aprofundados no estudo dessa variável. Um primeiro ponto diz respeito à natureza hierárquica do autoconceito. Grandes contribuições têm sido dadas a esse estudo pela teoria do processamento da informação, que tem ajudado na compreensão da natureza e importância dessa hierarquia. Embora se reconheça a importância dessa discussão, esse ponto não se constituiu no interesse deste estudo.

Outro ponto de destaque nas discussões tem sido compreender os efeitos que o autoconceito exerce sobre a vida das pessoas. Tem sido constantemente reafirmado nas pesquisas uma forte relação entre o autoconceito e a aceitação social e adequação dos indivíduos nas suas relações com os outros. No entanto, não se tem clareza do quanto essa variável pode ser determinante da qualidade das relações estabelecidas entre os indivíduos. Também não se consegue estabelecer uma relação de causa e efeito entre as variáveis, impossibilitando que os estudos nessa área sejam aprofundados. Ao lado disso, não se conseguiu até o presente momento avaliar o impacto dos efeitos social e cultural sobre o autoconceito. As pesquisas têm avançado nessa discussão somente tentando verificar as diferenças de gênero e problemas desenvolvimentais na estruturação do mesmo. 
No campo educacional persistem as dúvidas sobre a natureza das relações entre o autoconceito e o desempenho e sobre a eficiência dos programas para mudar o autoconceito. Este último tema talvez seja o menos explorado. Poucos estudos, como vistos na apresentação da revisão de literatura, têm se detido na avaliação e implantação de programas de apoio aos indivíduos que apresentam prejuízos nessa área. Até o momento os estudos do autoconceito têm verificado como se encontram os sujeitos em relação a si mesmos.

Por último, gostaríamos de destacar a grande quantidade de instrumentos de medição desse constructo, o que dificulta a padronização dos resultados. Há que lembrar também que a maior parte dos instrumentos usados no Brasil são traduções ou adaptações de instrumentos construídos para outras realidades sociais. Ao lado disso, há que se considerar que os estudos sobre evidências de validade e os dados de precisão nem sempre são conhecidos, e muitos não possuem informações sobre as normas para se comparar e avaliar as pessoas.

Esse fato, aliado ao grande interesse que este constructo tem despertado em estudiosos das mais diferentes partes do mundo e a importância atribuída a ele no comportamento, nas atividades sociais e na organização da afetividade dos indivíduos é que motivou o interesse pela construção e validação de um instrumento de medição do autoconceito para crianças e jovens do Brasil, e que segue apresentado a seguir.

\section{Participantes}

Foram analisadas as respostas de 555 estudantes, $281(50,6 \%)$ do gênero masculino e $274(49,4 \%)$ do gênero feminino. As idades variaram entre 8-16 anos, com uma média de 12, 12 (mediana e moda 12) e desvio padrão de 2,25. Esses estudantes freqüentavam de segunda a oitava séries do ensino fundamental, de três escolas da cidade de Campinas.

\section{Opção quanto à forma de mensuração}

Sendo o autoconceito descrito como a maneira que o indivíduo se percebe, a maneira de se medir tal percepção se dá pela autodescrição. Nesse contexto, pode-se apontar para duas técnicas na obtenção dessa medida.

Uma das técnicas refere-se descrição livre estimulada pela questão "Quem é você?". Foi introduzida por Bugental e Zelen (1950) e tem a vantagem de permitir ao indivíduo a manifestação livre, deixando que ele escolha as situações de referência para se autodescrever.
A outra técnica é a autodescrição baseada em itens previamente estabelecidos e que podem aferir tanto a medida de um autoconceito geral quanto uma de suas dimensões. Esta foi a técnica utilizada na construção do instrumento tratado neste estudo. 


\section{Construção do Instrumento}

A construção das frases foi um esforço conjunto de alguns alunos de pós-graduação do Grupo de Estudos e Pesquisa em Psicopedagogia da Faculdade de Educação da Unicamp. Na orientação dada para sua formulação constava a criação de situações específicas para cada um dos quatro ambientes ou contextos, quais sejam, o social, o escolar, o familiar e o pessoal. Terminada essa fase, fez-se um estudo daquelas que mais se referiam ao constructo autoconceito e das que restaram procurou-se identificar o elemento básico envolvido.

Valendo-se dessa informação, procurou-se manter os elementos básicos identificados para os quatro contextos, variando a circunscrição ao ambiente. Essa decisão deveu-se ao fato de que se queria identificar critérios que fossem o mais específicos possível para cada um deles, mas não para os outros. O instrumento piloto foi montado com um total de 128 itens, sendo 32 itens para cada ambiente ou contexto.

Para cada item o estudante tinha três alternativas de resposta (nunca, às vezes e sempre). Quando os itens ou assertivas eram negativos, as atribuições de pontos foram para a resposta nunca $=2$, às vezes $=1 \mathrm{e}$ sempre $=0$; e quando as assertivas eram positivas as atribuições de pontos foram para a resposta nunca $=0$, às vezes $=1$ e sempre $=2$.

\section{RESULTADOS}

\section{Estudo fatorial}

A análise fatorial foi utilizada para distinguir quais indicadores seriam mais característicos ou mais específicos de quatro contextos, quais sejam, social, escolar, familiar e pessoal. A medida de adequação da amostra de Kaiser-Meyer-Olkin $(\mathrm{KMO}=0,763)$ sugere que o grau de variância comum entre as variáveis é regular, possibilitando a explicação de uma quantidade de variância satisfatória. Por sua vez, o teste de esfericidade de Bartlett $\left(\chi^{2}=14823,431, \mathrm{gl}=6441\right.$ e $\mathrm{p}=0,000)$ indica que a matriz é apropriada para a extração de fatores. Analisando o scree plot (Figura 1), observou-se a possibilidade de extração de quatro ou cinco fatores.

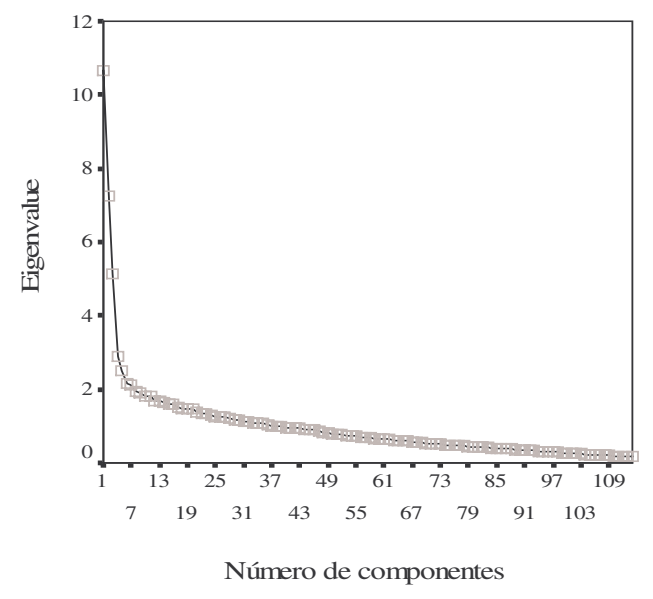

Figura 1: Gráfico de sedimentação dos eigenvalues.

Os dados foram estudados pela análise de componentes principais, rotação varimax, com eigenvalue igual ou superior a 1,0. Essa análise forneceu 34 fatores, explicando 64,55 da variância. Com base nessa análise e na consistência interna, estudada por meio do coeficiente alfa de Cronbach, foram eliminados itens, tanto pelo critério de saturação como para manter quatro fatores relacionados com os ambientes em estudo, quais sejam, o pessoal, o social, o escolar e o familiar. Nessas condições sobraram 20 itens, distribuídos em quatro fatores, explicando 41,09 da variância.

Tabela 1: Saturação (superior a 0,30) por fatores, com rotação varimax e normalização de Kaiser, eigenvalues e variância explicada

\begin{tabular}{lcccc}
\hline & \multicolumn{4}{c}{ Fatores } \\
& 1 & 2 & 3 & 4 \\
\hline S-Acho que sou o pior da turma. & 0,744 & &
\end{tabular}




\begin{tabular}{|c|c|c|c|c|}
\hline S-Acho que sou o mais burro dos meus amigos. & 0,733 & & & \\
\hline S-Considero-me o mais bobo dos meus amigos. & 0,587 & & & \\
\hline S-Sinto-me mais esquisito do que os outros. & 0,514 & & & \\
\hline S-Sinto que não consigo ajudar meus amigos. & 0,445 & & & \\
\hline S-Quando perco no jogo, tenho vontade de ficar só. & 0,437 & & & \\
\hline E-Considero-me o mais esperto da classe. & & 0,740 & & \\
\hline E-Penso que sou o mais divertido da classe. & & 0,653 & & \\
\hline E-Gosto de ser o líder nos trabalhos em grupo. & & 0,603 & & \\
\hline E-Imagino que sou o mais bondoso da classe. & & 0,557 & & \\
\hline E-Meus colegas concordam com tudo o que falo. & & 0,441 & & \\
\hline P-Acho que sou muito preocupado. & & & 0,674 & \\
\hline P-Quando erro, sinto-me muito mal. & & & 0,662 & \\
\hline P-Considero-me muito nervoso. & & & 0,621 & \\
\hline P-Tenho muitos problemas. & & & 0,542 & \\
\hline P-Tenho medo. & & & 0,513 & \\
\hline F-Tomo muito cuidado com as coisas em casa. & & & & 0,697 \\
\hline F-Fico alegre e contente quando estou com meus irmãos. & & & & 0,691 \\
\hline F-Digo a verdade quando estou com minha família. & & & & 0,675 \\
\hline F-Quando ajudo em casa faço tudo certo. & & 0,332 & & 0,447 \\
\hline Eigenvalues & 2,224 & 2,127 & 2,017 & 1,850 \\
\hline Variância explicada & 11,12 & 10,64 & 10,08 & 9,25 \\
\hline
\end{tabular}

Na Tabela 1, a primeira letra antes da frase indica a classificação inicial do item pelas diversas situações. Assim, pode-se observar que o fator 1, com 6 itens, refere-se ao ambiente social e explicou $11,12 \%$ da variância; o fator 2 com 5 itens relaciona-se ao ambiente escolar e foi responsável por $10,64 \%$ da variância total; o fator 3 com 5 itens caracteriza ao ambiente pessoal e explicou 10,08\% da variância; e, finalmente, o fator 4 com 4 itens concerne ao ambiente familiar e foi responsável por 9,25 da variância total.

$\mathrm{Na}$ Tabela 2 são apresentados os coeficientes de correlação item-total por escala. Apenas um valor foi abaixo de 0,30, valor esse considerado aceitável para esse tipo de análise (Guilford \& Fruchter, 1978).

Tabela 2: Coeficientes de correlação (r) item-total por subescala

\begin{tabular}{cccccccc}
\hline \multicolumn{2}{c}{ Pessoal } & \multicolumn{2}{c}{ Familiar } & \multicolumn{2}{c}{ Social } & \multicolumn{2}{c}{ Escolar } \\
Item & $r$ & item & $r$ & item & $r$ & item & $r$ \\
\hline P1 & 0,22 & F1 & 0,40 & S1 & 0,58 & E1 & 0,48 \\
P2 & 0,45 & F2 & 0,45 & S2 & 0,67 & E2 & 0,64 \\
P3 & 0,44 & F3 & 0,50 & S3 & 0,42 & E3 & 0,52 \\
P4 & 0,37 & F4 & 0,49 & S4 & 0,60 & E4 & 0,52 \\
P5 & 0,42 & & & S5 & 0,45 & E5 & 0,41 \\
& & & & S6 & 0,65 & & \\
\hline
\end{tabular}

Esse valor $(r=0,22)$ foi encontrado na subescala de autoconceito pessoal, na qual outros quatro valores estão acima dos 0,30 , perfazendo um total de 4 índices em 5. No geral, foi um item em 20, o que pode indicar uma boa consistência. Esse dado é indicativo de que essa escala necessitaria de algum estudo mais detalhado. As outras escalas, entretanto, apresentaram índices considerados de aceitáveis a bons.

Com a escala resultante desse estudo, foram calculados os coeficientes de consistência interna de
Cronbach, cujos valores de alfa foram de 0,62 para a subescala de autoconceito social; de 0,59 para a subescala de autoconceito escolar; de 0,62 para a subescala de autoconceito pessoal; de 0,59 para a subescala de autoconceito familiar; e, finalmente, de 0,78 para a escala de autoconceito geral. Esses valores podem ser considerados baixos, apesar de que há que se considerar o fato de o número de itens para cada subescala ser pequeno.

\section{CONSIDERAÇÕES FINAIS}


A análise fatorial permitiu a identificação itens que caracterizam os quatro ambientes que se pretendia, quais sejam, pessoal, familiar, escolar e social. Nesse sentido, pode-se ter uma avaliação de como as pessoas se percebem nesses quatro contextos, como também é possivel uma pontuação total, que representaria o autoconceito geral do individuo analisado. Em outros termos, as quatro subescalas permitem avaliar contextos ou ambientes sociais cuja natureza, apesar de funcionalmente dependentes, foi estabelecida mediante investigação fatorial, com vistas a isolar os elementos característicos para uma pessoa se analisar neles. Ao lado disso, o instrumento fornece também uma medida de autoconceito geral, soma dos quatro ambientes avaliados separadamente.

Esses dados apontam para o fato de que pessoas de 8 a 16 anos são capazes de discriminar indicadores e sua percepção deles para os distintos ambientes que convivem. Esses fato corrobora a perspectiva da multidimensionalidade do self defendida primeiramente por Mead (1934) e James (1890) e hoje por Marsh, Craven e Debus (1998) e Measelle, Ablow, Cowan e Cowan, (1998), entre outros.

A Escala de Autoconceito Infanto-Juvenil (EACIJ) pode ser aplicada de forma individual ou coletiva. No âmbito escolar o instrumento pode ser usado pelo professor, psicólogo ou pedagogo ou orientador educacional. Não se recomenda sua aplicação em pessoas com algum tipo de patologia psicológica ou psiquiátrica que afete seu estado de ânimo, sua organização perceptiva da realidade, que esteja com estado alterado de consciência, e em todas as outras condições que o aplicador considere que não sejam adequadas para o sujeito responder com sinceridade.

De maneira geral, o autoconceito pessoal refere-se aos sentimentos que tem sobre seu modo de ser e agir em diferentes situações, carregado de emoções ou lidando bem com elas. Os critérios para avaliar esse contexto caracterizariam crianças e adolescente que estão em um contínuo, que vai da presença de medo, erros, preocupação, nervosismo e problemas até sua ausência. Nesse sentido, uma pessoa que obtiver pontuação baixa nessa subescala se avalia como preocupada, nervosa, com medos; enquanto que uma pessoa com alta pontuação se vê como de bem consigo mesma, sem maiores preocupações, medos e ansiedades.

O autoconceito social tem como enfoque as relações sociais com os colegas e como a pessoa se percebe nessas relações. Os critérios se referem à avaliação de suas capacidades intelectuais, à vontade de ser igual ou melhor que os outros, o desejo de ajudar os amigos e ser ajudado quando necessitar. O contínuo de avaliação possibilita à criança e ao jovem a se avaliarem positiva ou negativamente frente a esses elementos. Assim, uma pessoa que obtiver pontuação baixa nessa subescala se avalia como não muito inteligente, boba, esquisita, com tendência a se isolar quando fracassa em alguma coisa e se vê também sem condições de ajudar seus amigos. Por sua vez, uma pessoa com alta pontuação se percebe bem intelectualmente, se compara ou se sente superior aos seus amigos, tem vontade de ajudar os outros e busca ajuda quando precisa.

Por sua vez, o autoconceito escolar trata de questões relativas às relações interpessoais que ocorrem no contexto escolar. Os critérios se referem à avaliação de suas possibilidades de liderança, de academicamente ser visto esperto e seus colegas aceitarem suas colocações, ao mesmo tempo em que é reconhecido como uma pessoa bondosa e divertida. Nesse contexto, uma pessoa que obtiver pontuação baixa nessa subescala se avalia como não muito esperto para os estudos, suas idéias são rejeitadas, não consegue liderar e acredita que não é visto como uma pessoa boa e divertida na escola. Em contraposição, uma pessoa com alta pontuação se vê bem intelectualmente, se sente mais ou menos líder e aceito pelos colegas de escola e se vê como divertido e bondoso.

Finalmente, o autoconceito familiar trata do comportamento adotado nas situações do dia-a-dia em casa com os pais e irmãos. Os critérios se referem à avaliação dos sentimentos em relação a irmãos, a ser cuidadoso com as coisas, dizer a verdade e fazer corretamente o solicitado pela família. Em decorrência, uma pessoa que obtiver pontuação baixa nessa subescala se avalia como triste e descontente com seus irmãos, relapso com as coisas da casa, fazendo suas tarefas na casa de qualquer jeito, fazendo coisas erradas e mentindo para seus pais. No entanto, uma pessoa com alta pontuação se avalia alegre e contente com seus irmãos, bem adequado e adaptado às exigências do lar e com um relacionamento de confiança e leal com seus pais.

Pode-se considerar que este estudo preliminar da Escala de Autoconceito Infanto-Juvenil revelou a possibilidade de um instrumento de avaliação com qualidades psicométricas satisfatórias, ainda que outros estudos necessitam ser feitos. Os que mais chamam a atenção se referem à busca de outras evidências de validade, estudo do instrumento em sua forma definitiva para analisar se a estrutura se mantém e outros estudos de precisão do instrumento.

\section{REFERÊNCIAS}


Adams, G. R. (1977). Physical attactiveness, personality, and social reactions to peer pressure. Journal of Psychology, 287296.

Adler, A. (1927). The theory and practice of individual psychology. New York: Harcourt.

Allport, G. W. (1966). Personalidade: padrões e desenvolvimento. São Paulo: Herder.

Baumrind, D. (1972). Socialization and instrumental competence in young children. Em W. W. Hartup (Org.), The young child. Reviews of Research, vol 2. (pp. 145-162). Washington, D.C.: National Association for the Education of young children.

Blascovich, J. \& Tomaka, J. (1991). Measures of self-esteem. Em J. P. Robinson; P. R. Shaver \& L. S. Wrightsman (Orgs.), Measures of personality and social psychological attitudes (pp. 115-160). San Diego, CA: Academic Press.

Bracken, B. A. \& Crain, R. M. (1994). Children's and adolescents' interpersonal relations: do age, race, and gender define normality? Journal of Psychoeducational Assessment, 12, 1432.

Bruschini, C. \& Ridenti, S. (1994). Família, casa e trabalho. Cadernos de Pesquisa da Fundação Carlos Chagas, 88, 30-36.

Buchanan, M. \& Wolf, J. S. (1986). A comprehensive study of learning disabled adults. Journal of Learning Disabilities, 1(1), 34-38.

Bugental, J. F. T. \& Zelen, S. L. (1950). Investigations into the "self-concept" The W-A-Y technique. Journal of Personality, 18, 483-498.

Burns, R. B. (1979). The self concept. London: Longman.

Byrne, B. M. (1986). Self-concept: academic achievement relations. An investigation of dimensionality, stability and causality. Canadian Journal of Behavioral Science, 18(2), 173-186.

Carneiro, G. R. S.; Martinelli, S. C. \& Sisto, F. F. (2003). Autoconceito e dificuldades de aprendizagem na escrita. Psicologia: Reflexão e Crítica, 16(3), 427-434.

Cooley, E. J. \& Ayres, R. R. (1988). Self concept and successfailure attributions of nonhandicapped students and students with learning disabilities. Journal of Learning Disabilities, 21(3), 174-178.

Coopersmith, S. (1967). The antecedents of self-esteem. San Francisco. Freeman.

Damon, W. (1983). Social and personality development. New York: Norton \& Company.

Durrant, J. E, Cunningham, C. E. \& Voelker, S. (1990). Academic, social and general self-concepts of behavioral subgroups of learning disabled children. Journal of Educational Psychology, 82(4), 657-663.

Estevão, C. \& Almeida, L. S. (1999). Dimensões do autoconceito e sua relação com o rendimento escolar. Psicologia Argumento, 17(24), 113-130.

Fini, L. D. T. (2000). Relações entre pais e adolescentes. Em F. F. Sisto; Oliveira, G. C. \& Fini, L. D. T. (Orgs.), Leituras de psicologia para formação de professores (pp. 163-176). Petrópolis: Vozes.

Furman, W. E. \& Buhrmester, D. (1992). Age and sex differences in perceptions of networks of personal relationships. Child Development, 63, 103-115.

Goldani, A. M. (1994). As famílias brasileiras: mudanças e perspectivas. Cadernos de Pesquisa, 91, 7-22.

Guilford, J. P. \& Fruchter, B. (1978). Fundamental statistic in psychology and education ( $6^{\mathrm{a}} \mathrm{ed}$.). New York: McGraw-Hill.
Hansford, B. C. \& Hattie, J. A. (1982). The relationship between self an achievement/ performance measures. Review of Educational Research, 52(1), 123-142.

Harter, S. (1985). The self-perception profile for children. Denver: University of Denver.

Harter, S. (1990). Self and identity development. Em S. S. Feldman \& G. R. Elliott (Orgs.), At the threshold: the developing adolescent (pp. 352-387). Cambridge: Harvard University Press.

James, W. (1890). Principles of Psychology. New York: Holt.

Jesus, D. M. \& Gama, E. M. P. (1991). Desempenho escolar: sua influência no autoconceito e atitude em relação à escola. Cadernos de Pesquisa da UFES, 1, 56-62.

Knowles, B. S. (1983). Academic success: tapping the emotions. Academic Therapy, 18(4), 437-442.

Lerner, R. M.; Orlos, J. B. \& Knapp, J. R. (1976). Physical attractiveness, physical effectiveness, and self-concept on late adolescents. Adolescence, 11, 313-326.

Lindner, M. S. (1992). The adjustment of children in nondivorced, divorced single- mother, and remarried families. Monographs of the Society for Research in Child Development, 57, 35-72.

Maccoby, E. (1980). Social development. New York: Wiley.

Machargo S., J. (1991). El profesor y el auto concepto de sus alumnos. Teoría e Práctica. Madrid: Escuela Espanõla.

Marsh, H. W.; Smith, I. D. \& Barnes, J. (1985). Multidimensional self-concepts: relations with sex and academic achievement. Journal of Educational Psychology, 77(5), 581-596.

Marsh, H. W., Craven, R. \& Debus, R. (1998). Structure, stability and development of young children's self-concepts: A multicohort-multiocasion study. Child Development, 69(4), 1030-1053.

Martins, S. R. S. (1997). Autoconceito em crianças repetentes e não repetentes: dois procedimentos de avaliação. Dissertação de Mestrado não publicada. Curso de Pós-Graduação em Psicologia, Pontifícia Universidade Católica de Campinas, SP.

Mead, G. H. (1934). Mind, self and society. Chicago: The University of Chicago Press.

Measelle, J. R.; Ablow, J. C.; Cowan, P. A. \& Cowan, C. P. (1998). Assessing young children's view of their academic, social and emotional lives: an evaluation of the self-perception scales of the Berkeley Puppet Interview. Child Development, 69 (6), 1556-1576.

Purkey, W. W. (1970). Self concept and school achievement. Englewood Cliffs, N. J: Prentice Hall.

Ribas, N. R. S. (1994). Estudo do autoconceito de escolares préadolescentes e adolescentes da escola estadual de primeiro grau Cícero Barreto de Santa Maria. Dissertação de Mestrado não defendida. Universidade Federal de Santa Maria, RS.

Ribeiro, M. A. (1987). O autoconceito de adolescentes segundo o sexo e a estrutura familiar. Dissertação de Mestrado não defendida. Universidade de Brasília, DF.

Seco, G. M. S. (1993). O autoconceito escolar em educadoras de infância: um estudo transversal. Revista Portuguesa de Pedagogia, 119-139.

Serrano, M. R. (1991). O autoconceito e a percepção de controle $e$ sua relação com o rendimento acadêmico. Dissertação de Mestrado não defendida. Programa de Pós-Graduação em Educação. Universidade Estadual de Campinas, SP.

Shavelson, J., Hubner, J. J. \& Stanton, G. C. (1976). Self-concept. Validation of construct interpretation. Review of Education Research, 46, 407-442.

Silva, J. C. R. (1999). O impacto do autoconceito no rendimento acadêmico. Dissertação de Mestrado não defendida. Programa 
de Pós-Graduação em Educação. Universidade Federal do Ceará, CE.

Stipek, D. J. (1981). Children's perceptions of their own and their classmates' ability. Journal of Educational Psychology, 73, 404-410.

Swayze, M. C. (1980). Self-concept development in young children. Em T. D. Yawkey (Org.), The self-concept of the young child (pp. 102-128). Provo: Brigham Young University Press.

Tamayo, A. (1985). Relação entre o autoconceito e a avaliação percebida de um parceiro significativo. Arquivos Brasileiros de Psicologia, 37(1), 88-96.
Wylie, R. C. (1979). The sef-concept (vol II). Lincoln. University of Nebraska Press.

Zimiles, H. L. \& Valerie, E. (1991). Adolescent family structure and educational progress. Developmental Psychology, 27(2), 314-320.

\section{Sobre os autores:}

Enviado: $15 / 10 / 2004$

Revisado: 20/11/2004

Aceito: $30 / 11 / 2004$

Fermino Fernandes Sisto: Doutor pela Universidad Complutense de Madrid, Livre-docente pela Unicamp e docente do curso de Psicologia e do Programa de Estudos Pós-graduados em Psicologia, da Universidade de São Francisco, campus Itatiba-SP. Endereço Eletrônico: fsisto@nipnet.com.br.

Selma de Cássia Martinelli: Mestre e doutora pela Unicamp e professora do Departamento de Psicologia Educacional na Faculdade de Educação da Unicamp, atuando na graduação e pós-graduação. 